\title{
Erratum to: Use of a Simulation-Based Capstone Course to Teach and Assess Entrustable Professional Activities to Graduating Medical Students
}

\author{
David H. Salzman ${ }^{1,2}$ - William C. McGaghie ${ }^{2}$. Timothy Caprio ${ }^{3}$ - Elizabeth A. Even ${ }^{4}$. \\ Kathryn Hufmeyer $^{3} \cdot$ Nabil Issa $^{5}$ • Eric Schaefer ${ }^{3} \cdot$ Jennifer Trainor $^{6}$. \\ Diane B. Wayne $\mathrm{e}^{2,3}$
}

Published online: 20 September 2016

(C) International Association of Medical Science Educators 2016

Med. Sci. Educ. (2016) 26:453-456

DOI 10.1007/s40670-016-0267-2

Due to an oversight during the production process, this article was published without the following acknowledgement:

The authors would like to acknowledge a grant from the Zell Family Foundation; the online version and PDF omit this. The Foundation supported this program through an education unrestricted grant that supported faculty salaries. The funder did not have any role in curriculum design, evaluation, analysis, or drafting of the manuscript.

The online version of the original article can be found at http://dx.doi. org/10.1007/s40670-016-0267-2

David H. Salzman

dsalzman005@northwestern.edu

Diane B. Wayne

dwayne@northwestern.edu

1 Department of Emergency Medicine, Northwestern University

Feinberg School of Medicine, 211 E Ontario St, Suite 200,

Chicago, IL 60611, USA

2 Department of Medical Education, Northwestern University Feinberg School of Medicine, Chicago, IL 60611, USA

3 Department of Medicine, Northwestern University Feinberg School of Medicine, Chicago, IL, USA

4 Northwestern Memorial Hospital, Chicago, IL, USA

5 Department of Surgery, Northwestern University Feinberg School of Medicine, Chicago, IL, USA

6 Department of Pediatrics, Northwestern University Feinberg School of Medicine, Chicago, IL, USA 